\title{
Quality of work life (QWL) situation in the Nepalese corporate sector
}

\begin{abstract}
Authors
Sulochana Shrestha:

Enthusiastic specialist having outgoing personality and result-oriented attitude in business management. me.silurita@gmail.com
\end{abstract}

Sujita Thapa: An aspiring professional with sound skills competence for total customer satisfaction in banking industry.

Laxmi Mangrati: Having a ambition to work for an organization of high repute with a great devotion on integrated marketing communications.

Pratima Devkota: An aspiring professional with sound knowledge, skill competence and attitude for integrated business management.

Rekha Rai: Envisions developing up-to-date business knowledge and practical skill to improve institutional performance by professional networking and collaboration.

Kabita Adhikari: Faculty Management

Key Words

Autonomy of work, compensation and rewards, job satisfaction and job security, quality of work life, relation and co-operation, training and development; work environment.

\begin{abstract}
Background: Existing literature on $Q W L$ and CG supports that effective compliance of CG is dependent on how the institution is nourished with the spirit of $Q W L$ and CG maintains relationship between the company's management, board of directors, shareholders, employees, and auditors and stakeholders. Moreover, QWL consider different components like autonomy of work, compensation and rewards, job satisfaction and job security, quality of work life, relation and co-operation, training and development, work environment.
\end{abstract}

Objectives: The main purpose of this paper was to investigate the factors, dimensions and policy implications to foster quality of work life ( $Q W L)$ situation in organizations, especially in the Nepalese corporate sector.

Methods: Fully based on qualitative desk review and analyses.

Results: This paper has attempted to establish relationship between the determinants of QWL situation and corporate governance (CG) from a positivists' perspective. In the present Nepalese context, several challenging factors, such as, employee attitude, working environment, opportunities, nature of work, stress, job challenges, development and career potential are affecting $Q W L$ attainment.

Conchsions: QWL promotes adequate and fair compensation, safe and healthy working condition, opportunity to use and develop human capabilities, opportunity to growth and security, social integration, constitutionalism, social relevance of work life; work and total life span of the people.

Implications: Robust QWL standardization, monitoring and evaluation be in place to govern all corporate entities in a meaningful manner.

Paper type: Review paper 


\section{Introduction}

In today's dynamic business environment, managing an organization has become a very much complex job. The organizations are forced to attract and retain a competitive workforce to become able to counter the ever-increasing competition. In this respect, quality of work life (QWL) focus seems to serve as an important instrument to boost employee morale and competence making them able to respond with improved level of productivity. As a result, QWL has assumed inversing interest and important in both industrialized as well as developing countries. Another scholar, Biswakarma (2015) has claimed that quality work environment factors are critical issues when examining the work life of employees with an aim to reduce absenteeism, accidents and attributes and at the same time, with an increment, productivity, institutional effectiveness, employee and economic development of the country as well. Hence, it is important to an organization to well-formulated HR practices, policies and executes them effectively to boost employee quality of work life.

QWL is a process of work organizations, which enables its members at all levels to actively participate in shaping the organizations, environment, methods and outcomes. This value-based process is aimed towards meeting the twin goals of enhanced effectiveness of organization and improved quality of life at work for employees. Moreover, quality of work life can be possible through induction training, motivated employees, job security, satisfaction, health and safety measures, teamwork, management leadership, employee compensation, empowering to employees, salary, wages and condition of service and reward system (Shanker, 2014).

Likewise, QWL increase individual productivity, accountability, commitment, better teamwork, communicator, improved morale, better understanding of what individual work for life balance, increase productivity and reduced stress. Additionally, corporate governance focuses on directing and controlling the companies. The essence of the corporate world lies in promoting transparency and accountability and in fulfilling the fair expectation of the shareholders. Similarly, QWL minimize the labor turnover and absenteeism, improve quality of work life, job design, career development, flexible work (Shanker, 2014; Ali, 2010).

Another scholar has defined that corporate governance as a broad term that describes the processes, customs, policies; laws and institutions that direct the organizations and corporations in the way they act administer and control their operations. It works to achieve the goal of the organization and manages the relationship among the stakeholders including the board of directors and the shareholders. It also deals with the accountability of the individuals through a mechanism, which reduces the principal-agent problem in the organization.

Consequently, the quality of work life (QWL) influences quality of life (QOL) of employees in organization. Technological advancement focuses on economic growth and productivity whereas QWL scale up the human and environmental values.On the other hand, growing number of women employees' level up awareness on working time, salary, child care and other facilities which enhance quality of work life. Additionally, salary and good benefits increase loyalty and favorable working environment, which improve good approach of employee retention in an organization (Narenhan, Harunnisa, Norfadzilla \& Freziamella, 2014). 
QWL is designated to improve employee satisfaction. Moreover, it strengthens workplace learning, better manage, building cooperation, restructuring task carefully, improving work environments and managing human resources. QWL boost QOL through spillover, segmentation and compensation. Spillover effect works life through affective work experience. Likewise, segmentation isolates experiences and affects the working attitude of the employees. Compensation included sufficient and fair remuneration, social integration and safe and healthy working conditions (Sirgy, Reilly \& Efraty, 2008) has examined QWL programs related to the working environment. QWL develop and reform the entire organizational structures, teamwork, quality circles and ethical corporate culture. Also, QWL improve job performance, job motivation employee loyalty, turnover rate, employee absenteeism and employee commitment to the organization (Sirgy, Reilly \& Efraty, 2008).

Corporate governance means the extent to which companies are run in an open and honest manner. It is a system approach by which companies are directed and controlled. The essence of the corporate world lies in promoting transparency and accountability and in fulfilling the fair expectation of the shareholders (Ali, 2010). Another scholar has defined that corporate governance as a broad term that describes the processes, customs, policies; laws and institutions that direct the organizations and corporations in the way they act administer and control their operations. It works to achieve the goal of the organization and manages the relationship among the stakeholders including the board of directors and the shareholders. It also deals with the accountability of the individuals through a mechanism, which reduces the principal-agent problem in the organization.

The primary objective of the present work was to assess the QWL scenario in Nepalese corporate sector. More specifically, this paper has attempted to --

a. assess the key element or factors influencing the QWL,

b. determine how the quality of work life effect on organization performance,

c. examine the strategies adopted by Nepalese corporate sectors,

d. determine the challenges, problems in implementing the QWL strategies,

e. identified the role of corporate governance in quality of work life,

f. procure the future implication in order to maintain QWL in Nepalese corporate sector.

Quality Work Life means having good supervision, good working conditions, good pay and benefits and an interesting challenging and rewinding job. High quality work life is sought through an employee relation's philosophy that encourages the use of quality work life efforts which are systematic attempts by an organization to give workers greater opportunities to affect their jobs and their contributions to the organization's overall effectiveness. It is the responsibility of the management to develop QWL among the employees to reduce the evil effects of lower level of QWL. Good corporate governance where there is transparency and accountability as well as close interaction among the employees forms the management could have positive impact in maintaining QWL.

For development-oriented economies like Nepal, and rapid change of competitive business environment the organization need to have competitive workforce to counter the compe- 
tition. To keep the competitive force in an organization the quality of work life is the important issue because it reduce the absenteeism, task error, conflict at work and turnover and improve the morale of an employees, production and institutional effectiveness. Biswakarma (2015) has stated that employee engagement and working conditions is the most affecting factors in quality of work life and the quality of work life is better and less stressful in non-financial sector than financial sectors. Likewise, Adhikari, Hirasawa, Takakubo and Pandey (2011) has identified that there is no equal employment opportunity for men and women, lack of governance, wage discrimination between male and female, low capacity utilization of organization and increased dissatisfaction among employees at work, poor labor policy. So, these finding shows that in the context of Nepal the quality of work life in corporate sector has not satisfied because of the poor implementation of corporate governance in an organization which creates the problem of inequality, stressed and unsatisfied. So, the attempt was made to study the overall quality of work life situation among the employees in Nepalese corporate sectors.

The present work has focused on issues, challenges, current scenarios facing quality of work life (QWL) situation with specific reference to the following research questions:

a. What are the key elements or factors to be considered important in promoting QWL situation in the Nepalese corporate sector at present?

b. How favorable are the prevailing national and institutional policies to promote QWL situation in the Nepalese corporate sector?

c. What are the likely outcomes of effective QWL compliance in the corporate sector in context of Nepal?

d. What are the ways forward to transform the overall QWL situation in the Nepalese corporate sector?

Quality of work life is the perception of employees' mental and physical satisfaction at work, which impact on the performance of employees towards the organization. If employees are satisfied with the working life they are positive towards their jobs, organization, management and colleagues and if not then increase employee absenteeism, reduce the productivity, increase the rate of employee turnover. So, the employees' performance matter a lot in organization they are the major components of organization who perform the activities of organization and lead towards the end results. Quality of work life is the quality of relationship between employees and total working environment. Paying attention to the needs of employees can benefit the company in terms of productivity, employee loyalty and company reputation, which represent the good governance as well. It is concern for human dimensions of work and relates to job satisfaction and organizational development. In order to transform of labor laws, healthy and hygienic culture, rules and regulation in the corporate sector QWL is essential. Similarly, in the corporate houses to empower the employee, motivate them, reduce the employee turnover and increase the productivity of the organization it works. This study would also be beneficial for the academic sectors. It works as the reference for the future researchers intending to undergo systematic inquiry in this particular domain of organizational management and administration. 
Quality of work life programmers are desirable for both employee and performance needs, because it acts a motivating factor for better working, comprehends conditions at employment, includes work environment and social integration and further seeks to employ the higher skills of work and provide an environment that encourages them to improve their skills. In order to maintain the good governance, effective working environment is needed. It is therefore essential to see the problem in its totality and hence planned approach is needed to study the quality of work life. If quality of life at work could be improved, it would benefit and reward the individual employee, the company, its customers and society as a whole with good governance. That is why it is necessary to talk about work life quality.

QWL is the relationship between employees and total working environment. Paying attention to the needs of employees can benefit the company in terms of productivity, employee loyalty and company reputation, which represent the good governance as well. It is a concern for human dimensions of work and relates to job satisfaction and organizational development. In order to transform of labor laws, healthy and hygienic culture, rules and regulation in the corporate sector QWL is essential. Similarly, in the corporate houses to empower the employee, motivate them, reduce the employee turnover and increase the productivity of the organization it works. This study is also beneficial for the academic sectors. It works as the reference for the researchers.

QWL programmers are desirable for both employee and performance needs, because it acts a motivating factor for better working, comprehends conditions at employment, includes work environment and social integration and further seeks to employ the higher skills of work and provide an environment that encourages them to improve their skills. In order to maintain the good governance, effective working environment is needed. It is therefore essential to see the problem in its totality and hence planned approach is needed to study the quality of work life. If quality of life at work could be improved, it would benefit and reward the individual employee, the company, its customers and society as a whole with good governance. That is why it is necessary to talk about work life quality.

For the purpose of making it simple to understand among the readers of this paper, the present researchers have established a set of operational definitions of the key terminologies used in this paper.

Autonomy of work: The autonomy is the ability of the employees to control over working situation. In autonomy of work the power are decentralized among the employees where employees can take part in decision-making process. Moreover, workers plan, coordinate, control, organize and make decision on work related activities. It provides opportunities of independency at work and provides authority to perform related task (Beh \& Rose, 2007).

Compensation and rewards: Compensation and Reward play as motivational factors. The best employees are awarded for motivating them and build sense of competition among employees. Moreover, compensation increases interest of employees toward their work. Moreover, payment of individual should be on the basis of their performance, responsibility handling, individual skills and knowledge and accomplishments (Mirvis \& Lawler, 1984).

Job performance: Job performance refers as the performance assessment and manage- 
ment which is the total expected organizational value how employees done their activities and execute it over a standard period of time (Pradhan \&Jena, 2017).

$J o b$ satisfaction and job security: Job Satisfaction is measured by appreciation, co-workers behavior, communication, job conditions, fringe benefits, nature of work, policies and procedures, personal growth, promotion and opportunities, security, supervision and recognition. Likewise, Job security affects individual performance in organization. Low job security increases sense of loose of job that is why they might not focus on their performance. On the other hand, High job security enhances employee's loyalty and productivity toward organization. The job security contains factors such as individual performance, performance of company and current economic situation (Nanjundeswaraswamy \& Swamy, 2013).

Organizational culture and climate: Organizational culture is driven by organizations values, vision, and norms and believes. Promotional opportunities and reward evaluation criteria control over the organization's policies. These two elements are significantly related with the quality of work life, which enforce on organizational commitment, job satisfaction and turnover. Moreover, higher the opportunities for the employees promote higher QWL. Organizational policies, procedures, leadership style, operations and general contextual factors are directly effect on the quality of work life. The organizational culture and climate is one of the dimensions, which control over the quality of work life (Mirvis \& Lawler, 1984).

Relation and co-operation: The communication between management and employees drive positive relation and co-operation between these parties. Employees who have authority to involve in decision-making activities, conflict management, and take part in meetings are more loyal toward the organization. Moreover, organization associates with career development activities of the employees and increase sense of belonging among them. Acceptance of employees is based on their skills, knowledge, capabilities, ability and traits rather than race, sex, and physical appearance. Thus, QWL leads to self-confidence and self-efficiency of employees toward their work and activities (Beh \& Rose, 2007).

Training and development: Training and development is necessary for the organizational who aimed for better performance of individual and group in organization. Training and development increase personal empowerment skills and ability. The goals of training and development are to improve organizational efficiency and improve quality of work life (Mirvis \& Lawler, 1984).

Work environment: Working environment denotes place where employees work together. It is denoting as the social and professional environment where worker interact with each other and build warm relationship. Work environment focus on safe and healthy environment, which ensure good health, decrease bad labor management relations and continuity of services. Employees are valuable asset of organization, they must have mentally and physically sound environment. These activities makes employees more cheerful and confident and highly productive (Lau \& May, 1998). 


\section{Methodology of works}

The study is mainly based on the exploratory research design heavily confined to literature review, peer group discussion along with the support of expert research person to determine the quality of work life in Nepalese corporate sectors. The study took around two months of time period to complete the overall research.

The study intends to gather qualitative data that describes the present policies, issues, dimensions, factors challenges and restraining factors of quality of work life in corporate sectors. Along with that the current scenario and practices adopted by enterprises in order to improve the QWL situation in corporate sectors has been analyzed. To accomplish the objective of our study more effectively the instruments like Internet, books, articles and magazines were referred. It has helped us to gain more knowledge and link our field of study to meet the objectives of our research work.

\section{Literature review on evolution of quality of work life (QWL)}

Quality of work life is about the individual's working life, which includes factors such as social relationship, health, income and other factor related to happiness and fulfillment. At early nineteenth century F.W Taylor has introduced Scientific Management Theory and creates awareness of human resources. The Scientific Management Theory mentioned about division of labor, close supervision, hierarchy and management principles. The continuous research on human behavior improves their job satisfaction, productivity and commitment. The quality of work life (QWL) means employees should be treated with respect, which increases sense of belongings toward the organization. Moreover, quality of work life enhances employee satisfaction and organizational effectiveness. In 1930s there was hazardous working condition, there was not employee protection rules, which increase risk in working environment. In 1940s unionization movement was taken place and it started to work for job security and economic gains for the employees. In 1950 os and 1960s different psychologists developed different theories regarding individual work life. The evolution enhances positive relationship between productivity and morale. The reforms bring equal employment opportunity and job enrichment schemes. Likewise, In 1970s the idea of quality work life was introduce which include values, human needs and aspirations. In 1972 international conference was conducted at Arden House, New York. International conference presented quality of working life and formed international council for quality of working life (ICQWL). After conference meeting held in Toronto in August 1981 on Quality of working life it becomes issue for the organization to boost Quality of work life of workers (Hian \& Einstein, 1990).

\section{Conceptual perspectives of corporate governance}

Before delving further on the subject it is very important to define the concept on corporate governance. There are vast amount of literature available on the subject, which ensure that there exist innumerable definitions of corporate governance. To get a fair view on the subject it would be prudent to give a narrow as well as broad definition on corporate governance. Ba- 
sically corporate governance involves a set of relationships amongst the company's management, its board of directors, its shareholders, its auditors and the other stakeholders of the company (Abid, Khan \& Rafiq, 2014). These relationships, which involve various rules and incentives, provide the structure through which the objectives of the company are set, and the means of attaining these objectives as well as monitoring performance are determined.

Corporate governance is the system of directing and controlling the whole corporation affairs on the behalf of the stakeholders by ensuring that the directors of company should aware about their duties, obligations and responsibilities to act for their company, and accountable with their stakeholders for their actions to manage the corporation soundly and effectively Sharma(2015). The OECD Principles of Corporate Governance states: Corporate governance is the framework through they distribute the responsibilities and authorities to complete their duties and it is also protect the right of shareholders and stakeholders, and transparent the information and disclosure timely within organization and define the role of board to evaluate and monitor the management and take accountability of their action.

The term corporate governance has been defined in many ways where many of the scholars have given their point of view on it. It is a system approach where the organizational rules and regulation are installed in an entity to give life by fulfilling all the legal requirements. The governance is complex and multi-faceted concept that is difficult to define in precise way so, it comprises of all aspects the mind map and a lot more areas and parties involved as mentioned above. The key aspect of corporate governance includes transparency of corporate structure and operations; the accountability of managers and the boards to shareholders; and corporate responsibility towards the stakeholders (Ali, 2010). While corporate governance essentially lays down the framework for creating long term trust between companies and the external providers of capital, it would be wrong to think that the importance of corporate governance lies solely in better access of finance.

Nowadays, companies around the world are realizing that the better the corporate governance, better in adding the value to their operational performance. However it improves the strategic thinking at the top by including the independent directors who bring a wealth of experiences and a host of new ideas. It also rationalizes the management and monitoring of risk that a firm faces globally. The decision making process will also be rationalized with the help of corporate governance by careful articulation of it through top management and it definitely integrates the integrity of financial reports. Hence, the companies with good corporate governance are uniformly transparent, systematic and with segregation of power between owners and the managers. The investors have appreciated such companies always. Boards of directors are the investors' custodians of trust and they take the decisions on their behalf in the interest of the company's progress with malice towards none and charity for all the stakeholders who impact the success or failure of the company. Therefore it is better to have the understanding of corporate governance from the narrow as well as from broader perspective. 


\section{Policy implications of corporate governance}

The practice of corporate governance in public as well as private sector has been increasing. Similarly the policy implication from the government side has been given much more emphasis because the organizations as well as government have also realized that the importance of corporate governance in each and every sector as well as what are the positive and negative consequences of not implying the corporate governance so the policy and its implication are being seen and applied in most of the organizations. Governance is taking the center stage in most of the discussions on public welfare issues is the state because despite good strategy programmers and adequate budgets, the implementation of these projects is not only slow but inordinately delayed so that the benefits to the stakeholders are in a trickle which ultimately is attributed to the failures of governance.

Business enterprises are equally sensitive for their success and failure on good corporate governance. Globalization, the liberal market led business environment, the new modes of business finances, the ever widening scope of stakeholders and the ever emerging new technologies are all jointly and/or severally enhancing the risks of doing business anywhere in the world including Nepal. Though corporate culture in Nepal is of a very recent origin and only slowly gaining ground, it is therefore, very important that good practices are inculcated in our corporate culture from the very beginning. FDI in infrastructural and hydro projects will definitely induce large investment in joint stock companies and will require effective and productive management structures by laws as well as by practices so as to meet the acceptance of all stake holders.

According to Agarwal (2019), corporate governance, the good governance of a country, is the backbone for the health of a company. If the corporate culture is sound and high standard Nepal can invite global corporation in terms of investment in large projects. The legal environment will pave the easy but it will not be enough to attract global investors unless our corporate culture matches global standards. It will be upon our chambers also to play the catalytic role through the awareness programs. The government also has to encourage by incentives good corporate practices. At least, the public sector boards can take the lead and show more transparency in disclosures of their performance and decision making process. Stress on merit and to be seen taking decisions on merit will be the first step.

Many corporations in Nepal as well as in the world have failed because the board of directors was not engaged in the operation nor were they organically involved in the strategy. They were guided by the briefings of the senior management and endorsed what was fed to them and took decisions without adding any value of their own. So long as the operation are smooth the role of the board of directors remains exalted but as soon as the threat starts looming the board of directors normally finds itself much maligned. The status is the same whether the company is private or public. Good corporate governance basically avoids the above. It predicts threats, weaknesses and gives reliable sustainability to its strengths and explores opportunities all the time to enhance shareholder's value. The Company Act of $\mathrm{Ne}-$ pal has to immediately acknowledge the necessity of improving the corporate governance of Nepalese companies and find ways to amend it in such a way that it compares well with international ones. Through bad corporate governance companies may end not with a bang 
but a whimper without anybody knowing it (Agarwal, 2019). Some of the policy implications on the corporate governance can be as such:

a. Workers voice needs to be addressed and participation in policy level decision-making should be enhanced. Dialogue culture between the employer and employees needs to be introduced. It is an effective tool for organizational culture change and for performance improvement and also reduces the dissatisfaction and unrest of firm production.

b. Legal aspect and social compliance has to be reviewed and monitored regularly and correction measure to be taken in time to time.

c. Appointment letter has to be issued for all level employees and career prospect to be ensured.

d. Paternal leave to be introduced along with maternity leave benefits for women.

e. Transport and housing facilities to be enhanced for all.

f. To ensure Employees satisfaction and Quality of work life in public as well as private enterprises. Employers need to embrace a certain level of employment security, job safety, free from job anxiety, reasonable wage, family day/leisure life, social life enjoyment opportunity, participation in decision-making.

Teamwork activities to be developed for more productivity/performance/training to be introduced in all level for performance and job satisfaction.

\section{Best practices of corporate governance}

Google: Google is one of the best examples of using the quality of work life in their organization. Google since 2007 every year held the number-one "Best Companies to Work For". They get over 2.5 million applicants which is equal to 6,849 per day and about 5 per minute. The reason behind everyone try to be in Google is their working environment where every employees are attracted to work. To attract and retain the workforce they need to be happy and motivated at work.

Google provide such environment where every employee wants to remain. Google has been one of the first companies who understand the need for employee and provide the flexible time scheduled and work as their terms for example they should go massage, swimming or any activities during working hour, or work from home with a sick child no one cares. They provide average salary $\$ 140,000$ for experienced workers and $\$ 93,000$ for the employees who have even less than one year which is a better salary than other company. Except monetary compensation, employees get clean work spaces, along with good cafeteria where varieties of food are available not only the varieties of food but also more healthier and tasty employees can take advantage of perks like free healthy and gourmet meals, laundry and fitness center, generous paid parental leave, and on-site childcare besides that employees also enjoy the various facilities like pools, bowling alleys, hair-cut, playground and massage at any time they want even in the middle of the workday all facilities available in organization through which they able to satisfied the physiological needs of employees. 
Google also provide facilities of health insurance, life insurance, financial planning to make the employees feel safer their future and satisfy the safety need. They allow kids and/ or pets to come to work, open office structure to communicate with anyone and makes all employees feel love /belonging in organization. They provide the freedom to employees how they'd like to work and also freedom to be a creative by encouraging employees to set their determined goals themselves, and create the environment from where they learn from their failures. There is internal competition within the company at the same project various teams work on it and the credit will get only those team who able to get the final product and respect their hard work which play as a role of motivators. And provide the opportunity of take responsibility, maintain the reputation, recognition and prestige and respect from other which satisfy the esteem need of employees. To fulfill self-actualization need Google donate to charities that the employees chose and also offering them one paid day a year to volunteer. These things increase employee happiness, which has a direct relationship with productivity.

They are not only able to satisfy the need of the employees but also have good corporate governance inside the organization by creating a culture of transparency in an organization where they share value across the organization. However, there is equality in an organization by hiring or providing opportunity to the different races of people like White, Asian, Black, Hispanic, Native American and Pacific Islander which shows diversity of culture in an organization and provides equal importance.

So, from analysis the working environment of the Google we see that the company has all the factors that help to maintain the quality of work life in the organization. They provide safe and healthy working condition, adequate and fair competition, and social relevance of work life, work and total life span, opportunity to growth and security, opportunity to use and develop human capabilities and as a result their employee performance is productive and employees are also satisfied from the working environment of the organization which makes them a successful company. Google's success at motivating and retaining its workforce like no other company so far has been able to do.

\section{Relationship between QWL and CG in the Corporate Sector}

In the era of cutthroat competition, the amount of time and energy people spent at the workplace has increased to a great extent. Therefore, it is important for employees to be satisfied about their life. Quality of work life is a philosophy, a set of principles, which holds that people are the most important resources in the organization as they are trustworthy, responsible and capable of making valuable contribution and they should be treated with dignity and respect (Gupta, \& Hyde, 2016). According to Keith (1989), quality of work life refers to favorableness and unfavorable of a job environment for the individual. It is a generic free that covers person's feelings about every dimension of work including economic rewards and benefits, security, working conditions, organization and interpersonal relationship and its intrinsic meaning in a person's life. The basic purpose of quality of work life is to develop work environment that are excellent for employees as well as for organization. The elements that are essential and relevant to an individual's quality of work life include task, the physical work environment, social envi- 
ronment within the organization, administrative system and relationship between life on and off the job. It could be argued that a better quality of work life makes employees satisfied with their job at their workplace and that contentment trickles down to their home and family life. The quality of work life is mainly concerned with the job security of employees, safety, proper hygiene that should be categorized for both male as well as female employees which needs to be made mandatory by the compliance of corporate governance so that the effectiveness and efficiency in the implication of it can be seen in the corporate sector.

The employees' satisfaction depends on the quality of work life provided by the organization. And to maintain the quality of work life depends on the corporate governance of corporate sectors. The factors that affect employee satisfaction were the healthy and suitable working environment, fair policies and practice, caring organization, appreciation, pay, promotion feel of belongings, initiation and leadership, feel of being loved, safety and security, challenges, responsibilities, creativity in job, personal interest and hobbies, respect from co-workers, relationship with supervisors, feedback, flexibility, and nature of work .The components of the corporate governance are fairness, transparency, responsibility and accountability Huillier (2014). Through the components of the corporate governance the organization provide the quality of life to the employees by making the organization policies and rules that support the employees and develop culture at where they have freedom to work and maintain the good working environment at where employees able to show their creativity. As already mentioned about the relationship between the quality of work life and corporate governance, there is a positive relationship between these two terms. However, more the implementation of quality of work life situation in an organization more will be the compliance of corporate governance.

In the context of Nepalese corporate sector, the implication of corporate governance has not been practiced effectively however the policies are made but implementation is quite slow as compared to others. As a result employee's turnover rate is also high in corporate sector resulting low productivity of the organization. Similarly, women needs to be considered and prioritized accordingly rules and regulations related to them need to be made so that the organization doesn't have to bear the loss of losing the qualified employees. Keeping these things in mind the study shows the importance of quality of work life and the relationship between the corporate governance in the real life scenario. Therefore, the relationship between the QWL and corporate governance is considered to be one of the inseparable parts of the organization.

\section{Conceptual perspectives of quality of work life (QWL)}

Quality of work life has always been up in studying organizational behavior. Quality of work life, in short, refers to the level of satisfaction, motivation, involvement and commitment of individual experience with respect to their lines at work (Gautam, 2010). The key elements of QWL in the literature include job security, job satisfaction, better reward system, employee benefits, employee involvement and organizational performance. According to the American Society of Training and Development (1979), it is a process of work organization, which enables its members at all levels to actively participate in shaping the organization's 
environment, methods and outcomes. This value-based process is aimed towards meeting the twin goals of enhanced effectiveness of the organization and improved quality of life for employees. Quality of work life has a direct relationship with the Quality of life of workers because Quality of work life does not only include the work-related factors such as welfare measures, benefit measures, safety measures, wages, relationship with colleagues, supervision, communication and participation in decision-making but also factors that broadly reflect life satisfaction and general feelings of well-being.

Broadly, the concept of QWL involves four major aspects: (i) safe work environment, (ii) occupational health care, (iii) suitable working time, and (iv) appropriate salary. The safe work environment provides the basis for a person to be happy at work. The work should not pose a health hazard for the person. The employer and employees are aware of their risks and rights, and could achieve a lot for their mutual benefit. The working time has been indicated by the State according to the legislation. QWL is defined in terms of the degree to which the work environment of an organization motivates effective job performance or in some cases the degree to which it safeguards the physical and psychological well-being of employees, and in other cases in terms of the degree to which it limits stress-inducing factors. High quality of working life has been equated with high employee motivation and with a high level of employee satisfaction (Lawler, 1975).

\section{Dimensions of QWL}

Job satisfaction Life survival, morale, effectiveness and employee maintenance are closely related with the provision of the quality of work life. Quality work life generally concern with the overall climate of work. Followings are the eight dimensions of quality of work life: adequate and fair compensation, safe and healthy working condition, opportunity to use and develop human capabilities, opportunity to growth and security, social Integration, constitutionalism, social relevance of work life and work and total life span.

Figure 1: The eight dimensions of $Q W L$

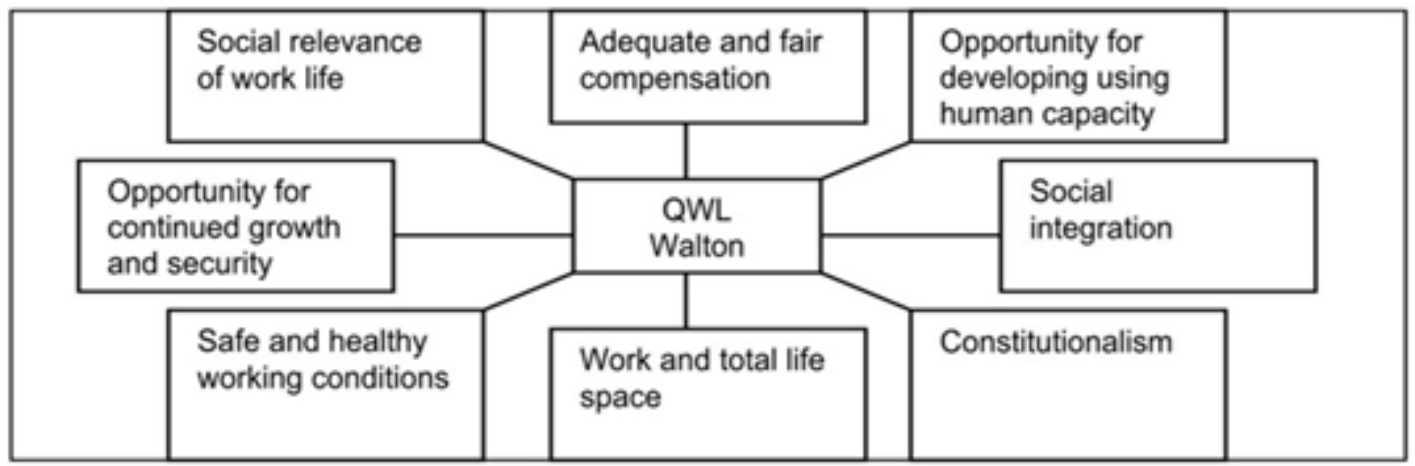

Source: Walton, R. E. (1973). Quality of working life: what is it? 
a. Adequate and fair competition: Quality of work life measures on the basis of adequate and fair compensation. There should be equitable balance between effort and reward. The compensation should help the employee in maintaining a socially desirable standard of living and should be comparable to the pay for similar work elsewhere. Several factors must be considered for determining such compensation, e.g. ability of the organization to pay, demand and supply of labor, cost of living of labor and job valuation, etc.

b. Safe and healthy working condition: Economic and social development of country has change the life style of blue collar and white collar. Improvement of the working style has change the perception of workers. Now, International Labor Office (ILO) covers the matter related to safety, health and working condition where they mention about training for safety, health and working conditions; people, safety, health and technical equipment; chemical risks to health; workplace climate; lighting and noise; ergonomics; working organization and working time and daily activity for safety; health and well-being. Modifying the working environment many companies are improving quality of work life of employees. This law safeguards employee's physical and emotional working conditions. Safe and healthy working condition provides the basis for the employee to enjoy working (Kinicki, Carson \& Bohlander, 1992).

c. Opportunity to use and develop human capabilities: Quality work life continuously works on the development of human capacities. The company focuses on scaling up the qualities of the employees through improving schemes or sponsoring different activities like education and training to them according to their needs. The productivity of the worker depends on their knowledge, skills and their working pattern. The companies overview employee needs, behavior and requirement and add value if necessary. The integral part of relevant factors for the human capacities development are provides certain work autonomy, use of the worker's skills and knowledge, to performance and task and have prior planning. Moreover, it describe about autonomy, multiple qualities, information on the total work process and relative self-control (Walton, 1973).

d. Opportunity to growth and security: Security and job stability is most important aspect associate with quality of work life. Job security provides the sense of assurance of employment security, which increases enthusiasm toward the working activities in organization. Quality of work like provides variation in job design, which motivate employee to use, develop their skills and knowledge, involvement, self-esteem and accept challenge obtained from the work. Thus, quality of work develops human capacities and security (Cascio, 2000). The associated aspects are capacity and knowledge development, scaling opportunity for worker using their skill and knowledge. It can be measure through career growth, training, personal growth, salary advancement prospects and job security (Das \& Vijayalakshmi, 2013).

e. Social integration: The personal relationships become an important dimension of the working life. The company ensures that every worker cooperate with each other and maintain personal relationships. The social integration symbolizes organizational structures, create supportive primary groups, social emotional support and encourages interpersonal openness among organizational members. Social integration involves process of changing and improving job, which motivate employees toward their work. It provides the employee with opportunity 
for the achievement, greater recognition and responsibility. Social integration makes closer social distance between employees and maintains peaceful social relations. Social integration focused on making safe, stable and prosperous workplace. It brings sense of closeness among the employees, which create harmony and enhance positive vibration in the workplace. Likewise, social integration strengthens the condition in workplace through maintaining peaceful social relations of coexistence, collaboration and cohesion (Ouppara \& Sy, 2012).

f. Constitutionalism: Constitution in the work organization is existence in order to protect workers from abusive actions. Moreover, it represents worker protection rights, labor rights, fair treatment, discussion, regulation for rules and regulations, opportunity to give opinion, privacy, freedom of expression, equality, fairness and respect individuality for their individual particular characteristics are factor related with constitutionalism(Das \& Vijayalakshmi, 2013).

g. Social relevance of work life: The companies always search for the improvement of their image and reputation. The companies are socially responsible. Moreover companies continuously work to enhance corporate image, corporate social responsibility, community integration, and quality of services, human resources policy, product liability and employment practices (Walton, 1973).

$h$. Work and total life span: Work and total life span directly related to the balance between time devoted to work and personal life. Work and total life span portrayed balance ole at work, time for family leisure, few geographic changes and time stability Spending quality time with family reflect positive impact which influence family routine, recreation possibility and leisure time and rest (Walton,1973).

\section{Additional insights on components of QWL}

There are different types of industries where QWL has been practiced. Different scholars have suggested with different composition of elements of QWL consideration across different industries.

Service industries: Beh and Rose (2007) have examined the component related to the services industries. Service sector is related with intangible goods, which include information sector services, transportation services, warehousing services, professional, technical and scientific services, health care services, waste management services, entertainment, education, hospital, hotel, social assistance services, after sale services, housekeeping, nursing and teaching, corporate advisory services, art and recreation services and so on. All these service sector focuses on the managing Quality of work life through various components. Some components related to QWL of service sector are adequate and fair competition, safe and healthy working environment, develop opportunities for human resource capabilities, opportunities for growth and security, social integration, constitutionalism and social relevance of work life

Corporate service: Corporate service integrated human resource and administration function in order to enhance service delivery quality and focusing on the welfare of all employees. Corporate advisory advices their client for advancing their business entity. Moreover, corporate service related with examining the legal, tax, finance, market and risk factors, which involve in making new changes to business. Corporate service provide advisory service related with company incorporation, registered agent, finance and banking, accounting and tax services, investment 
and stock exchange and so on (Mirvis \& Lawler, 1984). The major components of QWL related to corporate service are safe and healthy working environment, equitable and fair wages, equal employment opportunities, career advancement opportunities, trust in senior management, favorable working environment and balance between work and non-life work

Nursing and hospitals: According to Hoodles and Bourke (2009), nurses in hospitals feel monotony in the job due to routine work activities, which can negative effect on the QWL. Thus, QWL components related with the nurses in hospital are job satisfaction, work role ambiguity, conflict management, favorable working environment, reduce job stress, job involvement, organizational commitment, refreshment programs, balance of work and family, involvement in decision making activities, provide opportunities to learn new skills and recognition of efforts.

Manufacturing industries: The manufacturing industries are related to the trade based business where they manufacture raw materials into finished goods. Some examples of manufacturing industries are all food industries, chemicals, pharmaceuticals, textiles, machines and equipment. QWL in work place promote employee satisfaction and increase the commitment level of employees toward their work to be performed (Lau \& May, 1998). The components of QWL related to manufacturing services are job security, reward system, training, career advancement opportunities, participation in decision making activities, health and safety standards at work, amount of work to be done and social aspect and human relations of work life.

\section{Issues, Challenges and driving and restraining forces to QWL in Corporate Sector}

A good quality of work life (QWL) is essential for organizations to attract and retain employees. QWL programs are designed to improve employee motivation and job satisfaction. Considering the significance of the concept of QWL the present study attempts to examine critically the importance of quality of work life in Nepalese corporate sector with the compliance of corporate governance. It is difficult to best conceptualize the QWL issues. One of the major interpreters of QWL movement has proposed eight major conceptual areas for understanding QWL. These are (1) adequate and fair compensation, (2) safe and healthy working conditions, (3) immediate opportunity to use and develop human capacities, (4) opportunity for continued growth and security, (5) social integration in the work organization, (6) constitutionalism in the work organization, (7) work and total life space and (8) social relevance of work life (Kaur \& Randhawaa, 2012). Besides the mentioned issues there are other several issues that come in the way and some of them are as follows:

a. Pay: Various alternative means for providing wages should be developed in view of increase in cost of living index, increase in levels and rates of income tax.

b. Occupational stress: It is determined by the nature of work, working conditions, working hours, pause in work schedule, worker's abilities and nature and match with the job requirements.

c. Organizational health programs: These programs cover drinking and smoking cessation, hypertension control, other forms of cardiovascular risk reduction and family planning. 
d. Participative management and control of work: Worker's participation in management and decision-making improves QWL. Workers also feel that they have control over their work, use their skills, perform job better if they are allowed to participate in the creative and decision making process.

e. Recognition and rewards: Recognizing and rewarding employees and considering them as associates increases QWL. Congratulating the employees for their achievement job enrichment, offering prestigious designations to the jobs, providing well-furnished and decent work places are some means to recognize the employees (Kaur \& Randhawaa, 2012).

f. Job security: Job security leads to a sense of belongingness and association with the organization. Job insecurity reduces morale and leads to lower order QWL.

g. Adequacy of resources: For increasing the performance every work related resources must be at place and should match with stated objective.

Often it is observed that management fails to provide sufficient QWL, especially in the areas of job security, perks, and pay, for a fear incurring high cost. However, if management wants to develop a cohesive, loyal, and dedicated workforce, a clear and nurturing policy must be in place.

There are some of the restraining factors of quality of work life that are mostly seen in the organization and in order to overcome from those issues mentioned above restraining factors or the factors that affect to maintain quality of work life are as follows:

Work and life balance: Work and life balance deals with encouragement, and improvement in workers retention and turnover, reduces recruitment and training costs, reduces all forms of absenteeism, provides positive publicity for organizations, improves motivation and loyalty and thence productivity and increases customers satisfaction. Work life balance is all about flexible working, greater virtual communication, workload, and work time, high commitment and cognitive demands.

Role ambiguity: It is also one of the factors that affect the quality of work life if role and responsibility is not identifies properly then confusion might be created in the organization that simply can hamper the productivity of individual as well as of the organization. The clarity with which individuals perceive their work roles has been linked to several important organizational outcomes, including job performance, organizational commitment and Job Satisfaction.

Job insecurity: It is also one of the major factors that affect the quality of work life because job security helps to have a balanced work life so that each and every wants, desire will be fulfilled if there is job security and job guarantee. Nowadays most of the young generation keeps on switching from one job to another that leads to the insecurity and inconsistency in job. Therefore if organization fails to give job security then the quality of work life cannot be maintained.

Social support supervisor: Hawkins and Shohet (2004) also stated that a good supervisor could also help one to use one's resources better, manage one's workload and challenge in appropriate ways of coping. Supervision includes monitoring, implementing changes and maintaining the co-operative culture. Supervisory behavior is to co-operate with others in the 
team, persist in overcoming obstacles to complete a task, define the supervisor's decisions and voluntarily do more than the job -requires to help others or contributing to unit effectiveness.

Physical conditions: The perceived ability of an individual to perform accustomed functions and activities of daily living as part of the expectation of an organization largely depends on their physical conditions. A healthy work environment provides the basis for the person to enjoy working. Physical conditions include satisfaction with physical health.

Working conditions: Working conditions centers on the physical space that the employee is working in or a space that will be of use in the future. It also includes features like temperature, loud noise, crowding, poor lighting, cleanliness, ventilation, humidity and adequate tools. An ideal work condition should be mentally stimulating.

\section{Current Scenario and Practices of QWL in Organizations}

In the past the Government of Nepal (GON), to a large extent, remained inefficient to develop proper mechanism to monitor and supervise workplaces ensuring fair practices, such as standardized wage system and implementation of child labor standards (Gautam, 2010). Although the government enacted different acts in the past, it was not found to be very successful for their enforcement at the organization level.

Labor Act 1992, Child Labor Act 2000 and Trade Union Act 1992 are seemed to be enough, if they are honestly implemented. The government and employee are not so successful in implementing provisions of labor laws. The fact is that both the government and employers have failed to follow and implement proper mechanism of labor legislations. There are a number of lapses in the implementation of labor laws in Nepalese company. Due to lack of proper implementation of Act in Nepalese corporate sector the effectiveness is hardly seen for the productivity of the organization.

In today's work place we can find the better QWL as compared to previous decades. Employer and employees are more aware and educated about the QWL. In context of Nepalese organization, the International Labor Organization (ILO) has been played a key role for improving the quality of work life. The ILO monitors trends and developments regarding working time, work organization, and work-life balance around the world and analyses key and emerging issues, in order to provide ILO constituents and policymakers with practical information and research based policy advice grounded in state-of-the-art knowledge.

Government of Nepal (GON) is also taking a number initiative or measures to maintain and improve QWL situation. Although not adequate in the changing situation of Nepal, Government has been playing different roles to implement QWL initiatives.

First, it has formulated different labor related acts, rules and regulations. Second, the government has been trying to ensure that QWL mechanism is properly developed and organizations are also working in accordance with the rules and regulations. Third, since the government is still the largest employer in the economy government itself sitting on the negotiation table to bargain with trade unions in order to reach an agreement on different human resource and labor related issues (Adhikari, 2005). 
The Government of Nepal has been entitled to fix the minimum remuneration, dearness allowances and facilities of workers and employees on the recommendation of the Minimum Remuneration Fixation Committee. Similarly, the standard of safety required as per necessity is also published time to time in the Nepal Gazette. The Act makes sufficient provisions for keeping workplace free from dust,, and hazardous chemicals, adequate supply of light and water and health and sanitation facilities at work place. Similarly, labor unions are there to protect the rights of workers and employees considering provisions in the given labor legislations.

\section{Strategies for improving the QWL situation in the corporate sector}

The major objective of QWL is to create a favorable working environment where employees work together with mutual cooperation among each other and contribute to fulfill the organizational goals. In other words, it can be said, as QWL is the shared responsibility of both, the management and the employee. In the modern scenario QWL acts as a strategy of Human Resource Management for being recognized as the ultimate key for development among all the work system. This is an integral part of any organization towards its whole growth. The need for new perspective of QWL was needed because of the competitive advantage. The organization can improve the QWL situation through considering following aspects (Desslers, 2011).

Firstly, job enrichment where people may feel monotonous by doing same kind of work time and again. Kerzberg in his two-factor theory of motivation tried to use job as a medium of developing people and changing some organizational practices. Job enrichment leads to extension of job contents. It also develops competency of employees who voluntarily come forward to share higher responsibilities.

Secondly, maintaining the work life balance strategy where there should be a proper work life balance in which employees should achieve a satisfactory equilibrium between work and non-work activities as such parental responsibilities and wider caring duties, as well as other activities and interests. This entails adopting a flexible time option schedule for employees in order to balance organization requirements and personal expectations.

Thirdly, job rotation makes an employee to learn more about the new job at the new seat. Job rotation can reduce the problems associated with specialization such as boredom and monotony that are automatically removed, as the workers can become specialist at one prior task.

Fourthly, self-managed work teams which are also called as quality circles that can be defined as a small group of people generally 3 to 12 members who are used in involving and meeting for an hour every week to identify, analyze and solve the problems related to their work. The solutions are sent to the management for implementation. Quality circles develop a culture of participation among the workers. Self -managed team can encourage employees in equal participation and also sharing of knowledge among the individuals.

Fifthly, recognition of work life issues is related to work life that should be addressed by the company like why employee are happy and unhappy, do they need training. If these are addressed properly, they will able to build the people centered organization.

Similarly, commitment to improvement of QWL can be improved if the employees are themselves committed for improving the productivity and performance. The board through 
staff recognition and support programmers takes these steps. Board should prepare QWL reports on periodic basis to boost the system.

Autonomy at workplace where due delegation of authority and responsibility is considered to be an essential part of the organizational structure. People want freedom at workplace in their own way, in terms of forming teams and making decisions. If they are allowed to do so, it enhances the QWL.

The diverse work force of today does not want to work for fixed hours or days so there should be a flexible working hours in an organization. Employee wants flexibility in their work schedule so that professional and personal life can be managed together.

Quality of work life teams where the company Board members should form the combined team of managers and workers and all the issues and common themes must be identified. All issues must be addressed like loss of morale, lack of trust, increased intensity of work, reward; recognition etc. and commonly, managers and staff should arrive at solutions.

Workforce awareness is important to understand the thinking of the workforce, before launching any QWL program. Involvement of the managers, engineers, workers, and representatives and even outside consultants is necessary at the initial stage. All employees should be made aware for the introduction of QWL program and it's expected impacted.

\section{Impact of effective QWL in corporate sector}

Quality of Work Life (QWL) is a philosophy on employees' organizational life satisfaction. One of the challenging tasks for most of the organization is to maintain the organizational commitment, employee job satisfaction, and retention of experienced and trained employees. Kotze (2005) has stated that quality of work life has two objectives: one is to humanize the workplace and also to improve the quality of job experience of employee, and the other one is to improve productiveness and efficiency of the organization. Hence quality of work life can be considered as a response to the needs of employees as well as fulfilling the organizational need where series of improvement can be taken place in the organization. An efficient employee who is very much devoted towards his work and loyal towards his organization is considered to be a productive employee.

Goulet and Frank (2002) have stated that it is expected from the employees working for public organizations to be more committed towards their organizations than those working for profit private organizations since public organizations have more job security compared to for-profit private organizations, and that the literature has revealed the same results as well. The success of any organization depends on how it attracts recruits, motivates and retains its workforce. Organization needs to be more flexible so that they can develop their talented workforce and gain their commitment towards their work.

The effective QWL makes the employee more positive and motivated towards their work through the optimum utilization of the available resources in the organization so that the productivity of the company can be increased. Providing quality at work not only reduces attrition but also helps to reduce absenteeism and improve the job satisfaction. Not only does QWL contribute to a company's ability to recruit quality people, but also it enhances a com- 
pany's competitiveness. Common beliefs support the contention that QWL will positively nurture a more flexible, loyal, and motivated workforce, which are essential in determining the company's competitiveness.

QWL deals with making the work life and employee more qualified to increase productivity and efficiency of the employees so that the organization can achieve its objectives. Many studies have revealed that there is the positive relationship between the effective QWL and employee job satisfaction, organization commitment, and productivity. Dissatisfaction with the working life affects the organization life as well. The frustration, boredom and anger common to employee can be costly to both individuals and organization. Organization progress and profitability is directly linked with the satisfaction of its workforce. Therefore company needs to be very much organized as well focused on what it wants from the employees as well as how it can satisfy its employees (Biswakarma, 2015). A company that does not measure and improve employee satisfaction may face increasing turnover, declining productivity and limited ability to retain and attract qualified replacements. An effort towards QWL measurements helps in efficient and effective allocation of resources to enhance productivity and stability of the workforce that can lead to positive employee attitudes towards the work and the company, increased productivity and intrinsic motivation, enhanced organizational effectiveness and competitive advantage and enhance stakeholder relations and credibility.

\section{Policy implications for the promotion of QWL in Nepalese corporate sector}

Biswakarma (2015) has stated thatQuality of work life reflects the quality relationship between the employee and the total working environment of the organization. An organization is a place where group of people from different ethnic diversity come together and works for the achievement of common organizational goal. Quality of work life represents the concern for job security; job satisfaction of an employee's where people enjoy the work that they are performing within the organization in order to achieve the organizational goal.

In the context of Nepal, effective quality of work life can be maintained with the labor legislations Act that has been designed by the government of Nepal. The Act basically concentrates on improving the quality of work life of people for the betterment of employees, different provision related to the job security and safety, remuneration, allowance, retirement and related to other benefits that has been implemented in most of the organizations.

According to the legislation of Nepal both Labor Act 2074 and Child Act 2000 there has been clear deviation in the implementations of labor laws and fulfilling the gap between the union leaders that can be referred to a poor QWL situation in Nepalese firms. Hence looking at the current situation of Nepalese corporate sector still there are some changes that need to be implemented to bring the effective application of QWL in corporate sector has been addressed below:

In Nepalese corporate sector, the Human Resource Management Department should ensure that there is periodic review of employee needs to facilitate improvement in Quality of 
work life (QWL) and rise in the satisfaction level of employees. This should require adopting quality of work life (QWL) program such as job enrichment, and socio technical redesign into comprehensive efforts to improve the quality of working environment.

Efforts by the executive management of the organization by emphasizing the elements of quality of work life program be included in total quality management, workers' empowerment approaches / strategies to facilitate improved profitability of the organization.

Effective participation of an employee in the decision-making where the voice of each and every employee need to be addressed in an effective way. For this organization should come up with the policy of dialogue culture participation, it can be considered as a tool for the organizational culture change as well as the improvement in the performance that can reduce the dissatisfaction at work place.

Corporate sectors executive management should endeavor to improve quality of work life of employees by adapting methods that will make work meaningful by organizing workers into smaller, more cohesive, groups letting employees and groups make and participate in decision making process about what they do and how they do it and change the work schedule to suit a worker's needs.

Constitution of work management teams to design and redesign work to make it more meaningful is pertinent. Here work schedules should be made to be varied by compressing the work week, having flexible work hours and having part time worker option is encouraged.

Good organizational climate and healthy work environment that is conflict free be encouraged by executive management to facilitate high productivity, attainment. This will be attained through good working conditions, health and safety of the employees, good pay and benefits and good supervision.

Policies especially for women should be designed so that paternal leave as well as maternal leave can be benefited for both the parents.

Ensuring the quality of work life and employee satisfaction in an organization just to embrace the level of employment security, job security as well as job safety so that the employees will be free from the job anxiety, wage, leisure life, social life, enjoyment opportunity along with that the decision making capacity of the employees.

As we know there are two types of rewards like intrinsic and extrinsic rewards among these two extrinsic plays very important role. There are some extrinsic traits like jobs, wages and salaries, incentives, facilities and other benefits are more essential traits that are required to maintain the quality of wok life than that of the intrinsic traits of jobs. Working environment of the organization as well as the job security needs to be prioritized by the leaders just to maintain the quality of work life. Therefore, all the ingredients that will make work rewarding to employees such as job enrichment, socio technical redesign, rewards, self-managed teams, and work force awareness amongst others are encouraged by organization management. 


\section{Summary of findings}

In organizational setting, quality of work life (QWL) relates with the employee satisfaction which shows relationship between employees and total working environment and includes factors such as social relationship, health, income and other factor related to happiness and fulfillment.

On other hand, effective corporate governance (CG) may be achieved by empowering ethical value proposition in operational performance of organization by helping to maintain quality of work life through ensuring equality, responsibility, transparency, accountability in an organization.

The reason behind failure of Nepalese corporations may be partly because of lack of effective measures of corporate governance in place and their strict compliance.

The Company Act of Nepal has made different provisions to maintain good corporate governance in Nepalese corporations. For example, there has been provisions for employee participation in policy level decision-making, providing paternal and maternity leaves, staff transport and housing facilities, continuous tracking of employee satisfaction and quality of work life in public as well as private enterprises and so on.

However, management of institutions with the spirit of existing provisions for effective corporate governance has still remained still in infancy stage. As a result, the employees may be less satisfied with their work life resulting with higher degree of staff turnover in corporate sector that leads low productivity of the organizations.

\section{Recommendations}

Maintaining quality of work life in organization is one of the challenging works in corporate sector. In the context of Nepal, human resource management and development (HRM/D) department should ensure the improvement of QWL situation in respective organization in order to increase the satisfaction level of the employees. Every organization, government agencies and rest of corporate and development sectors should adapt and practice QWL programs as integral functional components. The following are recommendation for corporate sector, government and development agencies to adapt QWL situation and policies to promote good corporate governance.

a. The executive management of each organization should emphasize maintaining QWL by including programs like total quality management, worker's empowerment approaches and improving productivity and profitability of the organization.

b. The organizations should encourage employees to participate in decision-making activities to raise their voices in order to address their problems in effective way. For these activities, first of all organizations should develop policy documents to institute a culture of participation by means of open dialogues which may support attainment of perceived ease of working in an organization, ultimately resulting in improved level of performance.

c. In order to protect workers from abusive actions constitutionalism policy should be developed through worker enactment of protection rights, labor rights, fair treatment, regulation for rules and regulations, opportunity to give opinion, pri- 
vacy, freedom of expression, equality, fairness and respect individuality for their individual particular characteristics.

d. As QWL improves the image and reputation of organization, it should be made a shared mission of each organization to receive wider social acceptance of an organization. In fact, QWL should be recognized as part of organization's responsibility towards the society.

e. Internal and external conflict management improves the working style of workers. Good corporate governance always aims for the creation of environment which is free deconstructive conflict. Thus, human resource management and development (HRM/D) department should play role of facilitator, mediator, company spokesperson, internal consultancy, change agency and conflict manager.

f. QWL situation and employee satisfaction are connected with each other. The employee satisfaction can be leveraged providing employment security, flexible time table, fringe benefits, learning opportunities, rewards and compensation, improving co-worker behavior, flexible policies and procedures, appreciation, opportunity for personal growth and security. Moreover, there should be transparency in performance appraisal systems and regular training and development programs should be connected with employee perceived needs for learning and development.

g. In context of Nepal, governments at all levels should emphasize the enactment of policies concerning promotion of workplace autonomy, comparative compensation and rewards, training and development, continuous employee performance measurement and management, harmonizing organizational culture and climate, job security, social integration, development of human capacities and security, social relevance of work life, work and total life span and constitutionalism.

h. Most of the organizations adopt vertical communication techniques, which create communication gap between employees and senior management across different levels of organizational structures. Therefore, horizontal communication systems should be induced with the use of information communication technologies utmost.

From the above discussion in the context of Nepal, sustainable development and growth of organizations can be possible when they focus on implementation of good corporate governance with QWL sensitivity. Thus, organizations should create conducive environment by making equality law, rules, regulation, policies, procedures and strategies, which support QWL adherence situations. Thus, the regulatory authorities should play vital role to promote more conducive corporate governance situation in the country.

\section{Conclusions}

This paper aimed at the identification of factors responsible for QWL transformation in organizations. More specifically, it has attempted to establish relationship between QWL and corporate governance. After reviewing different studies related to QWL, it was found that 
there are several challenging factors significantly affecting the QWL situation in the Nepalese corporate sector. The factors associated to individual employee include knowledge, skills, expertise, experience regarding the task and responsibility assigned. Similarly, organizational factors include prevalence of rules and regulations, culture of employee training and development, level of organizational inputs for job security and workplace safety, organizational relationship, and so on.

Moreover, employee work with respect to whether they are handling dangerous tools, machinery, subject to availability of opportunities on the job for advancement and enrichment in quality of skills, learning for life, research innovation and prevalence of scope for self-development.

Similarly, the jobs that are boring, uninteresting, risky in nature, less secure and stressful are likely to invite organizational failure, at large. Such situations require prompt management action from the perspective of inducing QWL initiatives. Similarly, communication barriers between top management and bottom-line staff also serve as strong impediments against organizational transformation into 'learning organizations', which most of the workers favor.

Nepalese corporate sector can be transformed by means of collective efforts from the regulatory bodies, corporate management teams, employee unions and individual employees, who should consider prevalence of QWL as a pre-requisite for effective corporate governance.

\section{References}

Abid, G., Khan, B., Rafiq, Z., \& Ahmad, A. (2014).Theoretical perspective of corpornance. Bulletin of Business and Economics, 3(4), 166-175. Available at: https://www.researchgate.net/publication/272349786_Theoretical_Perspectives_of_Corporate_Governance. Retrieved on: January 30, 2019.

Agrawal, J. P. (2017, April 16). Corporate governance. New Business Age. Avaiable at :http://www.newbusinessage.com/MagazineArticles/view/1743. Retrived on: January 2, 2019.

Ali, M. (2010). Governance and good governance: a conceptual perspective. Dialogue (Pakistan), 1O(1), 66-77. Available at: https://pdfs.semanticscholar.org/2395/3c1185cb16f6coec5c17b5oc579d4dc66796.pdf. Retrieved on: January 29, 2019.

Alzalabani, A. H., (2017). A study on perception of quality of work life and job satisfaction: evidence from Saudi Arabia. Journal of Business and Management Review, 1-9. Available at: https://www. omicsonline.org/open-access/a-study-on-perception-of-quality-of-work-life-and-job-satisfaction-evidence-from-saudi-arabia-.php?aid=88056. Retrieved on: May 9, 2019.

Baba, V., \& Jamal, M. (1991). Routinisation of job context and job content as related to employee quality of working life: a study of Canadian nurses. Journal of Organisational Behavior, 379-386.Available at: https://onlinelibrary.wiley.com/doi/abs/10.1002/job.4030120503. Retrieved on: January 21, 2019.

Bagtasos, M. R. (2011). Quality of work life: a review of literature. DLSU Business and Economics Review, 2O(2), 1-8. Available at: https://www.researchgate.net/publication/275922756_Quality_of_ Work_Life_A_Review_of_Literature. Retrieved on: May 9, 2019.

Beh, L., \& Rose, R. C. (2007). Linking QWL and job performance: implications for organizations. Performance Improvement, 46(6), 30-35. Available at: https://onlinelibrary.wiley.com/doi/abs/10.1002/ pfi.139. Retrieved on: May 9, 2019. 
Biswakarma, G. (2015). A comparative study of financial and non- financial Institutions. Asian Journal of Managment Sciences, 19-26. Available at: http://literatipublishers.com/Journals/index.php?journal=AJMS\&page $=$ article\&op=view\&path\%5B\%5D=308. Retrieved on: May 7, 2019.

Biswakarma, G. (2015). Quality of work life in Nepal. Asian Journal of Managment Sciences, 19-26. Available at: https://www.academia.edu/18315066/Quality_of_worklife_in_Nepal. Retrieved on: January 19, 2019.

Cascio, W. F. (2000). Managing a virtual workplace. Academy of Management Perspectives, 14(3), 81-90. Available at: http://www.communicationcache.com/uploads/1/o/8/8/10887248/managing_a_virtual_workplace.pdf. Retrieved on: May 7, 2019

Das, T. V., \& Vijayalakshmi, C. (2013). Quality of work life: a strategy for good industrial relations. Advances in Management, 6(11), 8. Available at: https://www.revistaespacios.com/a17v38no3/ a17v38no3po5.pdf. Retrieved on: May 16th, 2019.

Desslers, G. (2011). Human resource management. (12th ed.). Boston: Pearson Publishing. Available at: https://scholar.google.com/scholar?q=Dessler,+G.+(2011).+Human+Resource+Management\%3B+12th+Edition,+Boston:+Pearson+Publishing.\&hl=en\&as_sdt=o\&as_vis=1\&oi=scholart. Retrieved on: January 29, 2019.

Gautam, D. (2010). Labor legislations for improving quality of work life in Nepal. International Journal of Laws and Management. 52(1), 40-53. Available at: https://www.researchgate.net/publication/244141805_Labor_Legislations_for_Improving_Quality_of_Work_Life_in_Nepal. Retrieved on: Feburary 1, 2019.

Gupta, B., \& Hyde, A. M. (2016). Factors affecting quality of work life among academicians. Anvesha, 9(1), 128-139. Available at: https://www.researchgate.net/publication/276864895_Factors_Affecting_Job_Satisfaction_among_Academicians_A_Comparative_Study_between_Gender_ and_Generations. Retrieved on: January 24, 2019.

Hoodless, M., \& Bourke, L. (2009). Expanding the scope of practice for enrolled nurses working in an Australian rural health service implications for job satisfaction. Nurse Education Today, 29(4), 432438. Available at: https://www.sciencedirect.com/science/article/pii/So260691708001305. Retrieved on: May 9, 2019

Hosmani A.P. \&Shambhushankar, Bindurani. R. (2014). Study on impact of quality of work life on job performance amongst employees of Secunderabad Division of South Central Railway. Research Journal of Management Sciences. 3(11), 8-11. Available at: http://www.isca.in/IJMS/Archive/v3/ i11/2.ISCA-RJMS-2014-85.pdf. Retrieved on: May 9, 2019.

Joshi, R. (2007). Qualityof work life of women workers: role of trade unions. Indian Journal of Industrial Relations, 355-382. Available at: https://www.jstor.org/stable/27768080?seq=1\#page_scan_ tab_contents. Retrieved on: January 26, 2019.

Kaur, K., \& Randhawaa, G. (2012). Quality of worklife issues: a comparative study of multinational an india food compantes of punjab. Gain Jyoti e-jouurnal. Available at: https://www.researchgate. net/publication/321376830_QUALITY_OF_WORK_LIFE_ISSUES_A_COMPARATIVE_STUDY_ OF_MULTINATIONAL_AND_INDIAN_FOOD_COMPANIES_OF_PUNJAB. Retrieved on: January 19, 2019.

Kinicki, A. J., Carson, K. P., \& Bohlander, G. W. (1992). Relationship between an organization's actual human resource efforts and employee attitudes. Group and Organization Management, 17(2), 135152. Available at: https://journals.sagepub.com/doi/abs/10.1177/1059601192172003. Retrieved on: May 7, 2019. 
Lau, R. S., \& May, B. E. (1998). A win-win paradigm for quality of work life and business performance. Human Resource Development Quarterly, 9(3), 211-226. Available at: https://onlinelibrary.wiley. com/doi/abs/10.1002/hrdq.3920090302. Retrieved on: May 9, 2019

Marie L'Huillier, B. (2014). What does corporate governance actually mean? Corporate Governance, 14(3), 30o-319. Available at: https://www.researchgate.net/publication/265732867_What_does_corporate_governance_actually_mean. Retrieved on: May 9, 2019.

Mirvis, P. H., \& Lawler 3rd, E. E. (1984). Accounting for the quality of work life. Journal of Organizational Behavior, 5(3), 197-212. Available at: https://onlinelibrary.wiley.com/doi/abs/10.1002/ job.4030050304. Retrieved on: May 9, 2019.

Nanjundeswaraswamy, T. S., \&Swamy, D. R. (2013). Review of Literature on Quality of Work life. International Journal for Quality Research, 7(2), 201-214. Available at: http://www.ijqr.net/journal/ v7-n2/3.pdf. Retrieved on: May 9, 2019.

Organization for Economic Corporation and development (OECD). (2019). About: Publishing. Paris: Author. Available at: http://www.oecd.org/about/publishing/. Retrieved on: May 8, 2019.

Ouppara, N. S., \& Sy, M. V. U. (2012). Quality of work life practices in a multinational company in Sydney, Australia. Procedia-Social and Behavioral Sciences, 40, 116-121. Available at: https://core.ac.uk/ download/pdf/81139725.pdf. Retrieved on: May 7, 2019.

Adhikari, D. R., Hirasawa, K., Takakubo, Y., \& Pandey, D. L. (2011). Decent work and work life quality in Nepal: an observation. Employee Relations, 34(1), 61-79. Available at: https://www.emeraldinsight.com/doi/abs/10.1108/01425451211183264. Retrieved on: May 7, 2019.

Randev, K. K., \& Nandan, T. (2016) Quality of work life indicators for sustainable development in the Indian Banking Sector. International Journal of Management and Applied Science, 2(12), 153-157. Available at: http://www.iraj.in/journal/journal_file/journal_pdf/14-328-1489642131153-157. pdf. Retrieved on: May 9, 2019.

Saiyadain, M. S. (2009). Human resource mangament. New Delhi India: Mc Graw Hill India. Available at:https://www.abebooks.com/book-search/title/human-resources-management/author/ saiyadain/.Retrieved on: January 23, 2019.

Sharma, P. K. (2015). Conceptual framework of corporate governance. Corporate Governance Practices in India, 12-27. Available at: https://link.springer.com/chapter/10.1057/9781137519368_2. Retrieved on: May 8, 2019.

Sirgy, M. J., Reilly, N. P., WU, J., \& Efraty, D. (2008). A work-life identity model of well-being: towards a research agenda linking quality of work life (QWL) programs with quality of life (QOL). Applied Research in Quality of Life, 3 (3), 181-202. Avaiable at: https://link.springer.com/article/10.1007/ s11482-008-9054-6. Retrieved on: April 19, 2019.

Walton, R. E. (1973). Quality of working life: what is it? Sloan Management Review, 15(1), 11-21. Available at: https://www.revistaespacios.com/a17v38no3/a17v38no3po5.pdf. Retrieved on: May 16, 2019.

Yvette. E.N. (2018).Google's secret to motivating their employees successfully. Journal of Strategic and International Studies, 19, 12(3), (1-6). Available at: https://www.researchgate.net/publication/326920436_GOOGLE'S_SECRET_TO_MOTIVATING_THEIR_EMPLOYEES_SUCCESSFULLY. Retrieved on: May 29, 2019. 